\title{
Obscénités renaissantes, sous la direction de Hugh Roberts, Guillaume Peureux et Lise Wajeman
}

\section{Michele Mastroianni}

\section{(2) OpenEdition}

\section{Journals}

\section{Edizione digitale}

URL: https://journals.openedition.org/studifrancesi/4622

DOI: $10.4000 /$ studifrancesi.4622

ISSN: 2421-5856

\section{Editore}

Rosenberg \& Sellier

\section{Edizione cartacea}

Data di pubblicazione: 1 avril 2012

Paginazione: 130-131

ISSN: 0039-2944

\section{Notizia bibliografica digitale}

Michele Mastroianni, «Obscénités renaissantes, sous la direction de Hugh Roberts, Guillaume Peureux et Lise Wajeman», Studi Francesi [Online], 166 (I | LVI) | 2012, online dal 30 novembre 2015, consultato il 19 novembre 2021. URL: http://journals.openedition.org/studifrancesi/4622 ; DOI: https://doi.org/ 10.4000 /studifrancesi.4622

Questo documento è stato generato automaticamente il 19 novembre 2021.

\section{(c) (i) $\odot$}

Studi Francesi è distribuita con Licenza Creative Commons Attribuzione - Non commerciale - Non opere derivate 4.0 Internazionale. 


\title{
Obscénités renaissantes, sous la direction de Hugh Roberts, Guillaume Peureux et Lise Wajeman
}

\author{
Michele Mastroianni
}

\section{NOTIZIA}

Obscénités renaissantes, sous la direction de Hugh ROBERTS, Guillaume PEUREUX et Lise WAJEMAN, préface de Michel JEANNERET, Genève, Droz, 2011 («Travaux d'Humanisme et Renaissance», CDLXXIII), pp. 493.

1 Questo densissimo volume offre i risultati di un gruppo di ricerca sulla nozione di oscenità nel Rinascimento francese costituito sotto gli auspici dell'Arts and Humanities Research Council (UK) ed è, in certo qual modo, continuazione del lavoro critico iniziato nel numero 14 degli «Studies in Early Modern France» (2010), intitolato Obscenity e diretto da Russell Ganim e Hugh Roberts. Come nota Michel Jeanneret nella Préface alla presente miscellanea, per quanto l'osceno sia di per se stesso marginale o clandestino, «paradossalmente il suo decentramento lo situa al centro di ciò che si può definire la letteratura, essa stessa per sua natura eccentrica» (p.11). Pertanto questo libro ci riconduce a dei meccanismi fondamentali della scrittura. I contributi qui riuniti sono $\mathrm{i}$ seguenti: Emily BUTTERWORTH, Defining Obscenity (pp.31-38); William MCKENZIE, Ovidian Obscenity in Renaissance France (pp. 39-47); Philip FORD, Obscenity and the 'lex catulliana'. Uses and Abuses of Catullus 16 in French Renaissance Poetry (pp. 48-61); Nelly LABÈRE-Helen SWIFT, Préliminaires à l'obscène: le Moyen Âge 'gaulois' (pp. 63-86); Emily BUTTERWORTH-Hugh ROBERTS, 'L'Obscène' in French Renaissance Texts (pp. 87-92); Hugh ROBERTS, Emblem Books (pp.93-100); Hugh ROBERTS, Erasmus (pp.100-105); Patricia simons, Gender, Sight and Scandal in Renaissance France (pp.115-128); Rebecca ZORARCH, «La terre encor aux ongles demouroit»: définir l'obscène dans le champ visuel (pp. 129-162); Cécile AULDUY, Archéologie d'un gros plan: sémiologie du sexe imprimé dans les «Blasons anatomiques du corps féminin» 
(1539-1554) (pp. 163-192); Jeanice вRоокs, Singing the Courtly Body: The 'chanson lascive' and the Performance of Obscenity (pp.193-206); Dominique BRANCHER, La révolte du Membre: épopée organique et dissidence stylistique dans la littérature médicale renaissante (pp. 215-236); Joseph HARRIS, Obscene Laughter and Renaissance Comedy (pp. 237-246); Hugh ROBERTS, L'euphémisme comique et les limites de l'obscénité au début du XVII siècle (pp. 247-261); Pollie BROMILow, Uncivil Conversation: Étienne Tabourot's "Escraignes dijonnoises" (1588) (pp. 263-273); Grégoire HoLTz, L'écriture de l'obscénité dans le récit de voyage aux Indes à la Renaissance (pp.283-300); Dominique BRANCHER, Poétique de l'insurrection: de l'impudeur naturelle des femmes (pp. 301-317); Marianne closson, Le sexe du diable: L'obscénité dans les textes démonologiques (pp.319-334); Michèle CLÉMENT, Construction de l'obscénité dans les narrations facétieuses: D'une scène à l'autre (pp. 335-348); Peter FREI, Le scandale de Rabelais: une Renaissance contre-nature (pp. 349-361); Emma HERDMAN, Censured and Censored: Reactions to Obscenity (pp.367-378); Ariane BAYLE, Six questions sur la notions d'obscénité dans la critique rabelaisienne (pp. 379-392); Lise WAJEMAN, Usages chrétiens de l'obscénité (pp.393-408); Guillaume PEUREUX, L'obscénité satyrique (1615-1622) (pp. 409-422); Russell GANIM, The Destruction and Re-Creation of Obscenity in Seventeenth-Century Pornographic Prints (pp. 423-438).

2 Mentre esisteva una ricca bibliografia consacrata alla nozione di oscenità in Rabelais (e in pochi altri testi), mancavano studi che permettessero di delineare un più vasto panorama concernente la produzione rinascimentale nella sua interezza. A questa mancanza hanno inteso porre rimedio sia il citato numero 14 di «Early Modern France» sia la presente miscellanea. Tuttavia, se la rivista esplorava una serie di singoli casi, il volume che ora segnaliamo si prefigge di offrire un quadro d'insieme dell' 'oscenità' rinascimentale. Il libro si compone di cinque parti, e «la sua organizzazione rende conto della natura profondamente problematica di ciò che è definito 'osceno' o è giudicato tale nel Rinascimento in Francia, ma anche del funzionamento e dei meccanismi dell'oscenità in un determinato spazio, della portata di un gesto (verbale, pittorico, scultoreo, teatrale) osceno, a partire dalla confusione delle frontiere tra ciò che è autorizzato e ciò che non lo è, fino a un'interrogazione sulla natura umana, passando attraverso l'analisi del valore politico di tale gesto» (p. 21). La prima parte esplora le difficoltà che si incontrano nel cercare di cogliere quello che ci sembra osceno o quello che poteva sembrare osceno nel Rinascimento. Si tratta qui di un'indagine essenzialmente lessicale e semantica («Le mot et la chose») che studia il rapporto tra i segni e i loro referenti così come lo concepiscono i filologi, i filosofi e i moralisti, ed anche i poeti e gli intellettuali in genere. I contributi della seconda parte («L'obscénité comme jeu de frontières») indagano sulle frontiere che si impongono gli autori, creando una continua interferenza fra ciò che è permesso e ciò che è vietato. La terza parte («L'obscène comique») mostra come l'indignazione suscitata dalle oscenità non impedisca che queste suscitino il riso, come l'effetto osceno risieda per una buona parte nel comico, e come il comico osceno non sia inoffensivo, anzi veicoli una forte carica sovversiva. Nella quarta parte («L'obscène: discours sur la nature humaine»), partendo dalla considerazione che nel Rinascimento la questione dell'oscenità si iscrive anche «nello scarto di un discorso antropologico sulla natura umana, coinvolgendo conoscenze diverse (religiose, mediche, filosofiche, storiche), e pertanto produce un effetto sovversivo in virtù di questo scarto stesso» (p. 277), ci si interroga appunto sulla natura umana, in un tentativo di definirla, servendosi della presente indagine sulla nozione di 'osceno'. Nella quinta parte («Politique de l'obscène») si tratta «della 
maniera in cui l'oscenità, nel corso del Rinascimento, ha potuto partecipare all'elaborazione di discorsi che suscitano reazioni diverse nello spazio pubblico in via di formazione e della maniera in cui questa oscenità ha potuto essere oggetto di appropriazioni per finalità genericamente polemiche» (p. 365). Per concludere, questo ricco volume delinea una mappa estremamente utile delle problematiche che pone l' 'osceno' nella letteratura, e nella cultura in genere, del cinquecento. 